Koehler, C., \& Weber, M. (2018). "Do I really need to help?!" Perceived severity of cyberbullying, victim blaming, and bystanders' willingness to help the victim. Cyberpsychology: Journal of Psychosocial Research on Cyberspace, 12(4), article 4. https://doi.org/10.5817/CP2018-4-4

\title{
"Do I really need to help?!" Perceived severity of cyberbullying, victim blaming, and bystanders' willingness to help the victim
}

\author{
Christina Koehler \& Mathias Weber \\ University of Mainz, Mainz, Germany
}

\begin{abstract}
Whether bystanders in cyberbullying help a victim or remain passive is based on multilayered cognitive processes. In particular, perceiving and interpreting an incident as an emergency situation, realizing one's own responsibility to intervene, and forming the intention to help are crucial preconditions for bystander interventions. The characteristics of information and communication technologies (ICTS) change and hamper these cognitive processes. Information and cues that guide individuals' reactions to offline victimization are missing in many online environments (e.g., seeing a victim's suffering). By applying a scenario-based experiment ( $n=240 ; 62 \%$ female; $M_{\text {age }}=21.3$ ), we investigate how cyberbullying incidents with differing degrees of severity (insults only vs. insults and threats) affect bystanders' perception of the incident, their tendency to blame the victim, and finally their reactions to cyber victimization (i.e., willingness to help). Our results showed that participants evaluated an incident that included threats and insults (as compared to insults only) as more severe; this in turn was related to a higher willingness to help the victim. In contrast, a seemingly less severe incident (containing insults only) fostered participants' tendency to ascribe (at least partial) blame for the incident to the victim. This victim blaming correlated with a lower tendency to support the victim. In conclusion, victims of seemingly less serious incidents in particular are at risk of experiencing prolonged suffering because bystanders fail to identify the emergency character of the situation and refuse to help.
\end{abstract}

Keywords: Cyberbullying; cyber aggression; victim blaming; bystanders; helping behavior

\section{Introduction}

Compared to face-to-face interactions, modern information and communication technologies (ICTs) have made bullies' jobs easier. Due to the ubiquity of online communication, offenders can cyberbully their targets at any time and from anywhere. Additionally, the internet is perceived as an environment where levels of both formal (effectiveness of legal norms) and informal control (presence of capable guardianship such as parents) are low (Cohen \& Felson, 1979; for online crime, see Pratt, Holtfreter, \& Reisig, 2010). Hence, victimization and perpetration rates of $10-40 \%$ among adolescents show that a noteworthy share of offenders make use of the opportunities that ICTs offer for bullying (Kowalski, Giumetti, Schroeder, \& Lattanner, 2014; Roberto, Savage, Ramos-Salazar, \& Deiss, 2014).

Yet, cyberbullying has been shown to result in serious consequences for the victim, which are comparable to those of offline victimization such as a decline in academic performance and in quality of family life (Patchin \& Hinduja, 2006). Even serious psychological conditions (e.g., anxiety and depression) can be triggered by cyber victimization (Didden et al., 2009; for a meta-analysis of risks associated with cyber victimization, see Kowalski et al., 2014). Again, the ubiquity of online communication is a crucial factor. While traditional bullying is (in most cases) physically limited to school grounds, a cyberbullying victim can be subjected to new attacks online almost 
continuously (Tokunaga, 2010). Further, the potentially large and unknown audience of cyberbullying attacks may nourish a victim's impression of being named and shamed in front of almost "everybody" (Dooley, Pyżalski, \& Cross, 2009). The intensity of perpetration may also be heightened due to the characteristics of online communication: Since bullies cannot see the victim's suffering, they may be less aware of the harmful consequences of their actions (Slonje \& Smith, 2008).

Several researchers have shown that the consequences of cyberbullying for the victim are considerably diminished when a victim receives support from those witnessing the incident (bystanders) (Dredge, Gleeson, \& de la Piedad Garcia, 2014; Salmivalli, Lagerspetz, Björkqvist, Österman, \& Kaukiainen, 1996). Yet, empirical evidence suggests that most bystanders remain silent or even join the bully in his or her attacks instead of helping the victim (e.g., Obermaier, Fawzi, \& Koch, 2016; van Cleemput, Vandebosch, \& Pabian, 2014). The reasons that inhibit observers to help in a situation of emergency have been conceptualized by Latané and Darley (1970) for offline situations and have already been studied in the context of computer-mediated communication (Obermaier et al., 2016). Mainly, the perception and evaluation of the situation, recognizing one's own responsibility to act, and finding suitable means for helping represent critical conditions for bystanders' prosocial reactions. However, research on the interplay of these conditions in the online environment remains a gap in research. Therefore, we aim to clarify the dynamics linking the perception and evaluation of a cyberbullying incident with bystanders' willingness to help the victim.

More specifically, we investigate how the severity of an incident predicts bystander interventions. Previous researchers have shown that bystanders are more likely to intervene in more severe incidents than in less severe ones (Bastiaensens et al., 2014, 2015; Kazerooni, Taylor, Bazarova, \& Whitlock, 2018; Obermaier et al., 2016; Patterson, Allan, \& Cross, 2017a,b). Researchers usually operationalize differences in incident severity as either an "objective" characteristic of different bullying incidents (e.g., Kazerooni et al., 2018; Obermaier et al., 2016) or as differing perceptions of the severity of the same incident (e.g., Patterson et al., 2017a). Following Bastiaensens et al. (2014), we replicate and extend these findings by combining both approaches. We experimentally manipulate a cyberbullying scenario so that two versions of the incident constitute different degrees of severity according to legal standards: insults and threats of physical harm (i.e., assault according to U.S. law) vs. insults only. Additionally, we establish our participants' perception of incident severity as the first of two mediators linking the "objective (legal)" characteristics of the incident with participants' intention to intervene.

Furthermore, we shed light on how the perceived severity of a bullying incident manifests in participants' intention to intervene. Allison and Bussey (2016) argued that moral disengagement (socio-cognitive process through which people detach themselves from humane acts, e.g., from helping) is a crucial mechanism here. Severe incidents might be less likely to be met with moral disengagement. Low moral disengagement in turn makes bystander intervention more likely (Song \& Oh, 2018; Thornberg \& Jungert, 2013). However, moral disengagement is a multifaceted construct. Here, qualitative research has shown that victim blaming-the tendency to attribute responsibility for the incident (in parts) to the victim -is a key dimension of moral disengagement when it comes to cyberbullying (DeSmet et al., 2014; Price et al., 2014). Victim blaming has been linked to intervention intentions in previous research (Schacter, Greenberg, \& Juvonen, 2016; Weber, Koehler, \& Schnauber-Stockmann, 2018; Weber, Schnauber, \& Ziegele, 2013); however, nobody has tested, with regard to cyberbullying, whether the degree of victim blaming depends on incident severity (i.e., whether victim blaming is also key in a potential connection between incident severity and bystander intervention in cyberbullying incidents). Therefore, we extend the current state of research by assuming that the severity of a cyberbullying incident reduces victim blaming. In turn, we expect that lower levels of victim blaming foster bystanders' willingness to help the victim and mediate the impact of incident severity on helping intentions.

Besides replicating previous results on the effects of incident severity and extending our insights by investigating two mediators in the cognitive process that guides bystander behavior (perceived severity and victim blaming), a third contribution to the research lies in the methodological design of our study. In their extensive review of research on cyber-bystanders, Allison and Bussey (2016) rightly pointed out that scenario-based experiments on bystander interventions are often beset with three main weaknesses: Firstly, most scenarios do not provide any context for the cyberbullying incident, but instead they merely present participants with the act of perpetration itself. Secondly, even identifying characteristics like names and pictures are omitted in these scenarios. In theory, both aspects contribute to a broader generalizability of the results; however, they impede the external validity 
because all the information that bystanders usually draw on for their interpretation of a bullying incident is missing. Thirdly, even when context is included in experimental scenarios, the design of the context is not informed by results from qualitative studies that might help to create realistic and conceptually meaningful incidents. Hence, we will test our hypotheses by presenting participants with cyberbullying scenarios of differing severity that include identifying information about the (fictive) victim and context regarding the bullies' alleged motivation for the attack. We chose the context following the results from qualitative studies that have illuminated the circumstances under which victim blaming is especially likely to occur.

\section{Incident Severity and Bystander Interventions in Cyberbullying}

Most adolescents and young adults have only experienced cyberbullying as bystanders, not as bullies or victims (van Cleemput et al., 2014; Vandebosch \& van Cleemput, 2009). However, bystanders are not merely background actors-their behavior crucially influences the process of perpetration and victimization. When confronting the bully, bystanders have a good chance of preventing further attacks (Salmivalli et al., 1996). By addressing and comforting the victim, bystanders enhance the victim's chances of productive coping (Dredge et al., 2014).

It is therefore troubling that only a minority of cyberbullying bystanders intervenes while most remain passive (and some even join the bully) (Obermaier et al., 2016; van Cleemput et al., 2014). Given that both the victim and the perpetrator perceive passivity as silent support for the bully (Namie \& Lutgen-Sandvik, 2010; Salmivalli, 2010), a passive bystander contributes to a heightened risk of severe and lasting victimization experiences.

Latané and Darley (1970) conceptualized the reasons for passivity among bystanders of an emergency situation. In step 1, bystanders have to be aware of an incident occurring. Then, they have to assess the incident as an emergency situation (step 2). It is only if they do asses it as such that they can feel responsible for intervening (step 3 ), and only then can they reflect on the possibilities of doing so (step 4) in order to decide whether they should actually intervene (step 5).

A crucial predictor for bystander intervention is the (objective) severity of an incident. Cyberbullying can take many forms-from making fun of someone or name-calling and insulting them to threats of physical harm (for an overview of different types of cyberbullying, see Rivers \& Noret, 2010). From a bystander's point of view, a more severe incident that, for example, includes threats of harm is more likely to unambiguously constitute an emergency situation (Allison \& Bussey, 2016; Shotland \& Huston, 1979). In their adoption of Latané and Darley's (1970) model for bystanders of cyberbullying, Obermaier et al. (2016) showed that this rationale could be applied to cyber victimization. They found that the severity of a bullying incident (i.e., the level of threats and insults used) predicted whether bystanders noticed a victim's emergency as well as whether they felt responsible for intervening. Bastiaensens et al. $(2014,2015)$ and Patterson et al. (2017a) provided evidence that more severe cyberbullying induced higher intentions of intervening among bystanders. Bastiaensens et al. (2014) also showed that these behavioral intentions were better explained by bystanders' perceived severity as compared to only drawing on an incident's "objective" severity.

Our first aim is to replicate these findings in order to broaden the evidence for incident severity as a basic and important explanatory factor of bystander behavior. However, and as an extension of Bastiaensens et al.'s (2014) argument, we consider perceived severity as a mediator, linking "objective" severity as it is indicated by different types of cyberbullying with bystanders' intention to intervene. We operationalize objective severity as insults vs. a combination of insults and threat of physical harm, with the latter representing the more severe type of perpetration according to legal standards (it potentially qualifies as assault according to the legal codes of most U.S. states, such as MT CODE ANN § 45-5-201). The rationale outlined above leads to the following assumptions:

H1a: A cyberbullying incident containing insults and threats is assessed as more severe as compared to an incident containing only insults.

H1b: As a consequence, bystanders' intention to help the victim will be higher when confronted with an incident containing insults and threats-mediated by the severity that bystanders' ascribe to the situation. 
However, the link between the type of incident as an "objective" indicator of severity, bystanders' ascribed severity and their willingness to help does not cover the whole process of psychological reasoning that arises when bystanders are confronted with an emergency situation. Based on Latané and Darley (1970), Obermaier et al. (2016) asserted that it is indeed whether bystanders feel sufficiently responsible for intervening that links severity to helping intentions. Alternatively, bystanders may ascribe the responsibility for resolving the incident to other bystanders or to the victims themselves. The latter may be the case when bystanders assume that victims are able to cope with a seemingly less severe incident without others' assistance (Patterson et al., 2017a,b). Another explanation is that they blame the victim for the incident and consequently hold the victim responsible for its resolution (DeSmet et al., 2014; Holfeld, 2014; Schacter et al., 2016; Weber et al., 2013, 2018).

\section{Victim Blaming in Cyberbullying}

Many bystanders refrain from helping-although they recognize that a situation constitutes an emergency, they do not feel sufficiently responsible to intervene. The reduced social cues approach (Dubrovsky, Kiesler, \& Sethna, 1991) provides an explanation for this lack of perceived responsibility in online environments. The low physical salience of the victim and hence a lack of information about her or his socioemotional reactions to the perpetration (DeHue, Bolman, \& Völlink, 2008; Patchin \& Hinduja, 2006) as well as a lack of the bystanders' physical presence (Brody \& Vangelisti, 2016) lead to reduced social control. That is, bystanders experience less external pressure to intervene and are hence more likely to give in to (alleged) justifications for remaining passive. One such justification is to deny that the victim is actually a victim. This happens when bystanders attribute (at least partial) blame for an incident to the victim (Bandura, 1990).

In cyberbullying research, victim blaming is mostly considered as one facet of moral disengagement (Allison \& Bussey, 2016, 2017; Song \& Oh, 2018). Moral disengagement refers to processes that allow individuals not to engage in self-sanctioning behavior that would usually result from inhumane behavior; thus, it facilitates inhumane behavior such as not helping people in emergencies. Moral disengagement is a multifaceted construct. In addition to victim blaming, it encompasses, for example, the distortion of harmful consequences or advantageous comparisons (Bandura, 1990). Following Allison and Bussey (2016), one may argue that more severe cyberbullying incidents are not only less ambiguous, but that they make the application of moral disengagement strategies more difficult. The more severe the incident, the more strongly the average bystander will evaluate not helping as inhumane, and the less likely moral disengagement strategies will suffice for countering this evaluation. In consequence, bystander intervention should become more likely (Song \& Oh, 2018; Thornberg \& Jungert, 2013). We empirically test this argument; however, given the very different facets of moral disengagement, we do not look at moral disengagement in its entirety, but instead we focus specifically on one component: victim blaming.

Qualitative studies have shown that victim blaming is indeed not only one, but a key component of moral disengagement (DeSmet et al., 2014; Price et al., 2014), and experimental research has connected victim blaming to lower helping intentions among bystanders of cyberbullying (Holfeld, 2014; Schacter et al., 2016; Weber et al., 2013, 2018). The just world theory (Lerner \& Miller, 1978) and the defensive attribution hypothesis (Burger, 1981) explain the occurrence of victim blaming. Just world theory posits that, based on self-protective needs, individuals are motivated to believe that the world is a just place, and that everybody is responsible for what is happening to her or him. In doing so, individuals are able to maintain the belief that negative events will not happen to them (Lerner, 1980). Instead of viewing a victim as a victim, they accuse her or him of having been provocative or assertive and hence of having caused the perpetration. This is especially true when bystanders gain the impression that the victim had some level of control over the situation (Holfeld, 2014; Weber et al., 2013) or interpret the perpetration as a reaction to an alleged norm violation (e.g., "not being clean" or "acting stupid"; DeSmet et al., 2014). We argue that victim blaming should therefore be especially sensitive to variations in the severity of a cyberbullying incident. A seemingly less severe incident that contains "only" insults (and no threats of physical harm) is more likely (though wrongfully) to be perceived as a conflict at eyelevel, with both the perpetrator and the victim having contributed to (and thus controlling) the contestation, or as a supposedly justified reaction to a victim's alleged norm violation. The evaluation of a cyberbullying incident as severe by bystanders is hence likely to affect bystanders' tendency to blame the victim. As researchers have identified attributing guilt to the victim as a reason for refraining from supporting the victim (Holfeld, 2014; Schacter et al., 2016; Weber et al., 2013, 2018), we hypothesize the following: 
H2a: An incident containing only insults (as compared to insults and threats) will lead to higher levels of victim blaming mediated via bystanders' evaluation of the cyberbullying incident as less severe.

H2b: Bystanders will be less willing to help the victim of an incident containing only insults (and no threats) since they evaluate the incident as less severe (mediator 1) and are more prone to attribute blame to the victim (mediator 2).

\section{Method}

\section{Design, Participant Characteristics, and Sampling}

We conducted a two-group online experiment (between-subject design) in May 2015 to test our hypotheses. We recruited 284 German-speaking participants by distributing the link to the online questionnaire via e-mail and social networking services (i.e., university mailing lists and Facebook). Out of the 284 participants who encountered the questionnaire on the landing page, 240 answered every question in the questionnaire; they represented the basis for our analysis. In our convenience sample, $62 \%$ of participants were female, $36 \%$ were male, and $3 \%$ of participants did not indicate their gender. The mean age was $21.3\left(S D=5.7\right.$, Age $_{\operatorname{Min}}=14$, Age $\left._{\text {Max }}=50\right)$, and $76 \%$ of the participants attended the upper secondary branch of the German educational system. With respect to cyberbullying, $65 \%$ of participants in the sample reported that they had observed cyberbullying at least once in their lives. Hence, the majority of the participants in our sample could draw on previous experiences as bystanders. A total of $31 \%$ had been victimized online, and $11 \%$ stated that they had bullied someone else online at least once in their lives. These prevalence rates correspond with the commonly reported incidence rates for cyber victimization and perpetration as well as bystander experience among pupils and adolescents (Modecki, Minchin, Harbaugh, Guerra, \& Runions, 2014; Vandebosch \& van Cleemput, 2009).

We randomly assigned the participants to two treatment conditions that represented different types of a cyberbullying incident (insults only vs. threats and insults). The distribution of our sample between the two treatment conditions was slightly uneven (insults only: $n=114$; insults and threats: $n=126$ ). The sociodemographic characteristics of our participants did not differ significantly between the treatment conditions (gender: $\chi^{2}(2, N=240)=0.59, p=.744$; age: $t(238)=-0.49, p=.632$; education: $\left.\chi^{2}(5, N=240)=1.91, p=.862\right)$. The same held true for participants' previous experiences as cyberbullying bystanders $\left(\chi^{2}(2, N=240)=0.59, p=.745\right)$, victims $\left(\chi^{2}(2, N=240)=3.61, p=.164\right)$, and perpetrators $\left(\chi^{2}(2, N=240)=0.49, p=.785\right)$.

\section{Procedure}

After entering the questionnaire via the landing page, participants were exposed to a fictive cyberbullying incident with the severity of the incident as the independent variable. Following Allison and Bussey's (2016) argument, we created a cyberbullying scenario that included identifying information about the (fictive) victim and the context regarding the perpetrators' alleged motives in order to strengthen the external validity. We chose the information about the victim and the context according to the results of prior research, again following suggestions from Allison and Bussey (2016). As it was our aim to test whether the severity of cyberbullying incidents could hamper victim blaming as a key moral disengagement mechanism, we created a scenario that, according to prior research, was likely to provoke victim blaming. We chose a male name for the victim ("Thomas") because Weber and colleagues (2018) found that male victims of cyberbullying in particular are at risk of being blamed for the incident. We chose the name "Thomas" because it is a frequently used name in the country where the study was conducted. Furthermore, it was explained Thomas' personal hygiene was an issue already prior to the incident, because in DeSmet et al.'s (2014) study, they referred to this explicitly as an example of a case when bystanders readily engaged in victim blaming.

We presented the scenario as follows: Thomas was not very popular among his classmates, and they often made jokes about his personal hygiene. After Thomas had worn the same t-shirt for several days, his classmates began to harass him by posting messages on his Facebook wall. After introducing our study participants to this background information, we showed them a fictive Facebook profile that contained five comments from Thomas' alleged classmates (four boys and one girl). In one version of this scenario (less severe), the bullies left comments containing insults and asking Thomas to change his t-shirt (e.g., "Don't you have any other t-shirts in your 
wardrobe?"). In the second version (more severe), these insulting comments were augmented with threats against Thomas (e.g., "A shower doesn't help anymore. You had better go die!"). Put simply, one stimulus version only contained insults, whereas the second version contained insults and threats. In doing so, we aimed to create stimulus versions that differed in their degree of severity with respect to the incident that we presented to the participants. This seemed plausible given the fact that-as opposed to the insults-the threats indicated explicitly that there was potential physical harm to the victim and thus may have qualified as an assault according to U.S. legal standards (e.g., MT CODE ANN § 45-5-201). Also, the risk of physical harm has been shown to be a critical feature for a problem situation to be classified as an emergency (Shotland \& Huston, 1979). The authors of the comments, the overall number of comments, the number of likes for each comment and the general information on the fictive Facebook profile were kept similar across treatment conditions. In sum, our scenario was characterized by the typical features of online victimization (as they are conceptualized on the basis of the reduced social cues approach, cf. Brody \& Vangelisti, 2016; DeHue et al., 2008; Dooley et al., 2009; Dubrovsky et al., 1991; Patchin \& Hinduja, 2006): The victim had no possibility of knowing who and how many people had observed the incident. From the perspective of a bystander observing the incident, one could assume that the victim did not know that she or he had seen the derogatory comments. Moreover, bystanders were only able to see the attack, but they could not see Thomas' (the fictive victim's) reaction to it. These specific features of online victimization create an ambiguous situation for perceiving, evaluating, and interpreting the incident itself as well as one's own willingness to intervene.

After being exposed to the cyberbullying incident, we asked the participants to evaluate the severity of the incident, their tendency to blame the victim, and whether they would be willing to help the victim. All items for each question were randomized to prevent biases due to the order of items. Finally, we debriefed the participants about the fictive nature of the incident and all of the persons involved in it.

\section{Ethical Aspects}

Since the study is based on an online-experiment, one might raise the question what information was given at which point in time to our participants and how other ethical aspects were handled. First, we fully complied with the American Psychological Association (APA) ethical standards as well as with research guidelines provided by the German research foundation (country, where the study was conducted). Right in the beginning of the study, on the landing page, participants were informed about the length of the questionnaire, they were given contact information to the authors of the study, they were informed that participation was voluntary and that they could opt out at any time, and that all the data was collected anonymously and for scientific inquiry only. As such, participation in the study was voluntary, open to everybody, no registration was required, and we did not offer any incentives. With respect to the issue of our study, participants were informed in general terms that they were participating in a survey on the topic of cyberbullying. Yet, the fictive nature of the incident was not disclosed to them until the very end of the experiment (i.e., the final page of our online questionnaire contained a debriefing).

We decided to use only complete data sets (i.e., we had not to handle missing values), because participants were not given the option to answer "prefer not to say"; instead they were not forced to answer all questions/evaluate all items of the questionnaire, but could skip them.

\section{Measures}

Perceived severity. We asked participants to evaluate the severity of the incident via seven semantic differentials on 5-point scales. The respective question read as follows: "How would you evaluate the incident with respect to the following aspects? nasty-not nasty (reverse coded), embarrassing-not embarrassing (reverse coded), hurtfulnot hurtful (reverse coded), funny-sad, encouraging-humiliating, humorous-in bad taste, undignified-dignified (reverse coded)" (The instruction for evaluating these items read as follows: "Please indicate your assessment of the incident by choosing the attribute that best describes your evaluation. You can use the three options in between to graduate you answer"). The Cronbach's alpha for the resulting scale was $a=.75$.

Victim blaming. To establish participants' tendency to (partially) attribute blame for the cyberbullying incident to the victim, we presented them with four items similar to those that Weber et al. (2013) developed by drawing on the just world theory (Lerner \& Miller, 1978): "Thomas had it coming," "Thomas has provoked the incident," "It is 
Thomas' fault that his classmates reacted to this situation in such a way," and "Thomas could have prevented the incident from happening." All items were rated on 5-point scales ranging from $1=\mid$ do not agree at all to $5=\mid$ fully agree. The reliability of the scale was $\alpha=.75$.

Willingness to help. We established the participants' willingness to help the victim using seven items based on the items that Bastiaensens et al. (2014) developed. The items covered a wide range of possible intervention strategies that differed primarily in whether the assistance was given privately or publicly (e.g., "I would console Thomas in private," "I would make the bullies aware of their misconduct by sending them a private message on Facebook," and "I would publicly share a comment on Facebook in which I confront the bullies" on 5-point scales from $1=$ I do not agree at all to $5=$ I fully agree). We conducted an explorative factor analysis to test whether the difference in public or private support measures constituted a different dimension of participants' willingness to help the victim. However, the result was a one-factor solution (principal component analysis, oblique rotation [i.e., direct oblimin]; Kaiser-Meyer-Olkin measure $=.81$; all factor loadings were above .40 as Field (2013) suggested; $41 \%$ explained variance). Thus, the participants seemed to regard public and private support measures in a comparable way, suggesting that we calculate one aggregate index from all the items. The internal consistency of the scale was satisfactory, with the Cronbach's $a=.76$.

Sociodemographic variables. At the end of the questionnaire, we measured the participants' main sociodemographic characteristics (age, gender, education) and their previous experiences as a victim, bully, and/or bystander of cyberbullying. For the latter, participants were directly asked whether they had experience with bullying on the internet and it was specified in terms of having received/sent/seen text posts/pictures that derogated and/or contained content that was mean about others/oneself.

\section{Data Analysis}

We conducted the mediation analysis using the PROCESS (v2, 16.3) procedure for SPSS 23 (Hayes, 2013). The treatment conditions were represented by a dummy-coded independent variable $(0=$ incident with insults only; $1=$ incident containing threats and insults). Significance of indirect effects was assessed using bias-corrected confidence intervals (bootstrapping, $m=10.000$ ).

\section{Results}

\section{Preliminary Analysis}

In what follows, we present a descriptive analysis of our data before moving on to hypothesis testing. We include the means, standard deviations, reliability scores, and bivariate correlations for the main variables in Table 1 . The participants in both treatment conditions evaluated the incident as relatively severe (if one considers that 5 was the scale maximum). Yet, the average rating of those in the less severe treatment condition was significantly lower $(M=4.43, S D=0.5)$ than the one in the (more severe) treatment condition with an incident containing insults and threats $(M=4.7, S D=0.37, t(238)=-4.821, p<.001)$. The tendency to blame the victim was comparably low in both treatment conditions, and there were no significant differences between the two groups. The same held true for participants' willingness to help the victim. The correlations between the variables showed a comparable pattern for both treatment conditions: Participants' perception of the severity of the incident and their tendency to blame the victim were significantly negatively correlated $\left(r_{\text {insults }}=-.43, p<.001 ; r_{\text {insults+threats }}=-.42, p<.001\right)$. The same held true for victim blaming and participants' willingness to help $\left(r_{\text {insults }}=-.36, p<.001 ; r_{\text {insults+threats }}=-.24, p=.008\right)$. In contrast, participants' evaluation of the incident with respect to its severity had a significant positive correlation with their willingness to comfort the victim $\left(r_{\text {insults }}=.31, p=.001 ; r_{\text {insultstthreats }}=.26, p=.003\right)$. All the correlations indicated a medium-large effect size. In sum, the descriptive analyses indicated that participants' perceived severity constituted a key variable in the relationship between incident severity, victim blaming, and willingness to help.

We aimed to investigate how bystanders evaluate and interpret cyberbullying incidents and how they-based on these considerations-formed their intention to help. Thus, we ran ANOVAs as a preliminary analysis to compare whether participants with different experiences (never vs. once vs. several times) as bystanders differed with respect to our main variables. While participants with different bystander experiences did not differ with respect 
to their tendency to blame the victim $(F(2,239)=0.28, p=.756)$ or their willingness to help $(F(2,239)=1.74, p=.178)$, their evaluation of the incident as severe differed significantly with respect to their previous experience as observers of such incidents. Participants who had observed a cyberbullying incident several times in the past rated the incident as significantly more severe than participants who had never seen such an attack of online victimization $(M=4.66, S D=0.38$ vs. $M=4.51, S D=0.51 ; F(2,239)=3.77, p=.024)$. Those who had seen such an incident only once in their lifetime did not differ significantly from the other two groups.

Table 1. Means, Standard Deviations, Reliability, and Bivariate Correlations for the Main Variables.

\begin{tabular}{|c|c|c|c|c|c|c|c|c|c|}
\hline \multirow{4}{*}{ Variable } & \multirow{4}{*}{ Cronbach's a } & \multicolumn{8}{|c|}{ Treatment Condition } \\
\hline & & \multicolumn{4}{|c|}{$\begin{array}{l}\text { Insults Only } \\
(n=114)\end{array}$} & \multicolumn{4}{|c|}{$\begin{array}{l}\text { Insults + Threats } \\
(n=126)\end{array}$} \\
\hline & & \multirow[t]{2}{*}{$M$} & \multirow[t]{2}{*}{$S D$} & \multicolumn{2}{|c|}{ Pearson's $r$} & \multirow[t]{2}{*}{$M$} & \multirow[t]{2}{*}{$S D$} & \multicolumn{2}{|c|}{ Pearson's $r$} \\
\hline & & & & 1 & 2 & & & 1 & 2 \\
\hline 1. Perceived severity & .75 & $4.43^{a}$ & 0.50 & & & $4.70^{a}$ & 0.37 & & \\
\hline 2. Victim blaming & .75 & 2.21 & 0.80 & $-.43 * \star \star$ & & 2.11 & 0.76 & $-.42 * \star *$ & \\
\hline 3. Willing-ness to help & .76 & 2.92 & 0.76 & $.31 * \star \star$ & $-.36 * \star \star$ & 3.05 & 0.77 & $.26 * \star$ & $-.24 * \star$ \\
\hline
\end{tabular}

Note: $N=240$. For all indexes: $\operatorname{Min}=1$ and Max $=5$

${ }^{a}$ Significant difference with $t(238)=-4.821, p=.000$

$\star * p<.01 .,{ }^{* * *} p<.001$

\section{Hypotheses Testing}

We ran a sequential mediation model to test our hypotheses (Model 6 from Hayes' (2013) PROCESS macro) (see Figure 1). The model contained the type of incident as the independent variable, the perceived severity of the incident as the first mediator, participants' tendency to blame the victim for the incident as the second mediator, and their willingness to help as the dependent variable. We also estimated the direct effects of the type of incident on victim blaming and willingness to help the victim in order to estimate a full model.

In line with our hypotheses, participants evaluated the cyberbullying incident containing threats and insults as more severe compared to the incident that contained only insults and no threats $\left(\beta=.30, b=.27, p<.001 ; R^{2}=.09\right.$, $p<.001 ; \mathrm{H} 1$ a supported). Additionally, evaluating the incident as severe significantly correlated with participants' willingness to help. The more severe the participants evaluated the incident, the more they were willing to intervene in favor of the victim $(\beta=.20, b=.33, p=.005)$. Accordingly, the indirect effect of the type of incident on participants' willingness to help the victim mediated via the participants' evaluation of the incident as severe was significant (indirect effect: $\beta=.06, b=.09,95 \% \mathrm{Cl}[0.03,0.18] ; \mathrm{H} 1 \mathrm{~b}$ supported). In sum, if the victim of the cyberbullying incident was attacked with threats and insults, participants perceived the incident as more severe, which made them more likely to support the victimized person. Additionally, victim blaming was significantly related to the participants' notion that the incident was severe, with a less negative evaluation of the incident being accompanied by a higher level of victim blaming $\left(\beta=-.44, b=-.76, p<.001 ; R^{2}=.18, p<.001\right)$. The indirect effect of the type of the incident on victim blaming mediated via participants' assessment of the incident's severity was also significant (indirect effect: $\beta=-.13, b=-.21,95 \% \mathrm{Cl}[-0.33,-0.12]$, H2a supported). Therefore, victims of cyberbullying incidents that bystanders perceive as not very severe run a higher risk of being assigned (a part of the) blame for the incident.

Victim blaming significantly correlated with participants' willingness to help $(\beta=-.21, b=-.21, p<.001$ ). Participants who were more prone to blaming the victim were also more reluctant to assist the victim. Finally, the indirect effect of the type of the incident on willingness to help mediated via the participants' evaluation of the incident's severity and their tendency to blame the victim was significant (indirect effect: $\beta=.03, b=.04,95 \% \mathrm{Cl}[0.02,0.09] ; \mathrm{H} 2 \mathrm{~b}$ supported). Participants perceived an incident containing only insults (and no threats) as less severe; consequently, they were more prone to attribute guilt to the victim and were ultimately less willing to support her or him in this emergency situation (variance of the dependent variable explained by all three predictors: $R^{2}=.12$; $p<.001$ ). The total indirect effect (i.e., the sum of all indirect effects) of the type of incident via perceived severity and victim blaming on participants' willingness to help the victim was significant $(\beta=.06, b=.11,95 \% \mathrm{Cl}[0.03$, 
0.21]). The two indirect effects of incident severity on willingness to help were significant despite the fact that neither victim blaming nor willingness to help overall differed between treatment conditions (see the preliminary analysis). This is because the two direct effects from incident severity on victim blaming and willingness to help, though insignificant, masked the indirect effects in the simple group comparison. That is, we indeed needed a mediation model in order to fully analytically grasp the processes at work that linked incident severity and bystanders' helping behavior.

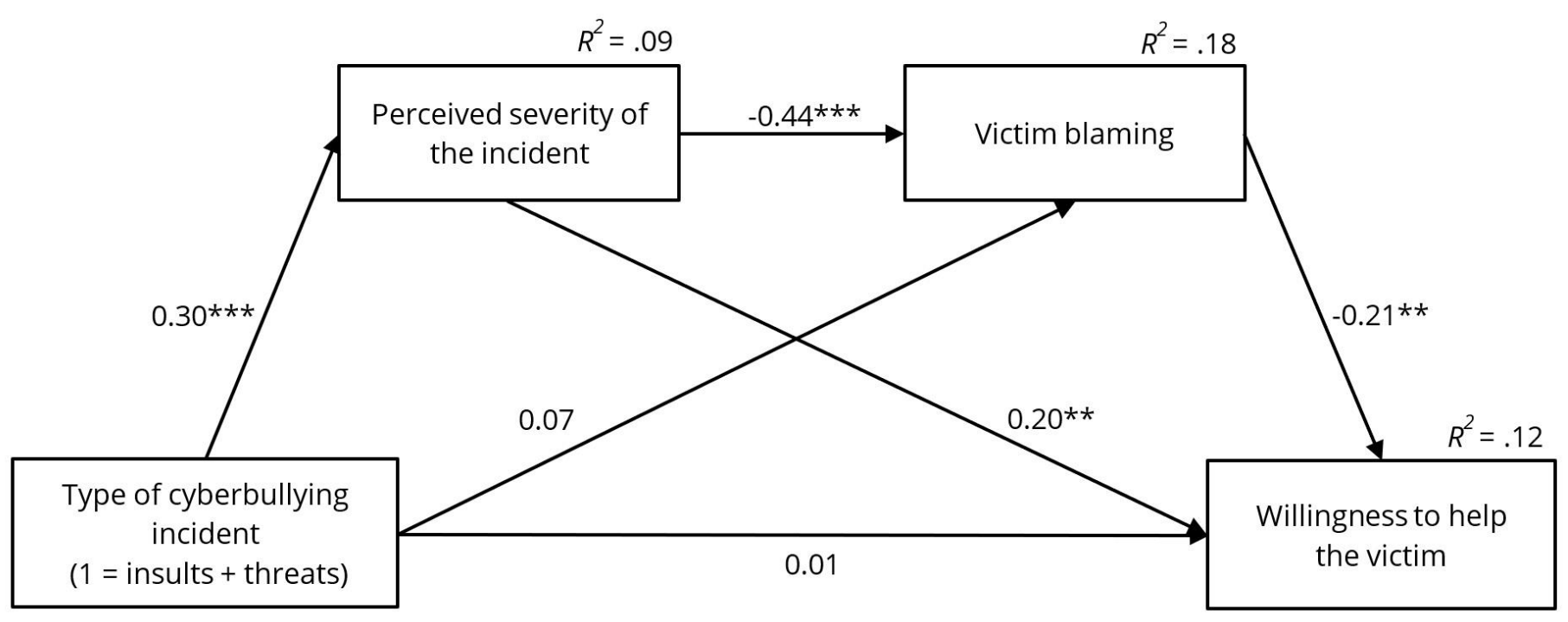

Figure 1. Mediation model, standardized coefficients, ${ }^{*} p<.05,{ }^{*} p<.01, * * * p<.001$

Indirect effects with bias-corrected confidence intervals obtained through bootstrapping $(\mathrm{m}=10,000)$

type of incident $\rightarrow$ Perceived severity of the incident $\rightarrow$ willingness to help: $\beta=.06,95 \% \mathrm{Cl}[0.03,0.18]$

type of incident $\rightarrow$ Perceived severity of the incident $\rightarrow$ victim blaming: $\beta=-.13,95 \% \mathrm{Cl}[-0.33,-0.12]$

type of incident $\rightarrow$ Perceived severity of the incident $\rightarrow$ victim blaming $\rightarrow$ willingness to help: $\beta=.03,95 \%$

$\mathrm{Cl}[0.02,0.09]$

Total indirect effect: $\beta=.06,95 \% \mathrm{Cl}[0.03,0.21]$

\section{Discussion}

We aimed to better understand what aspects of a cyberbullying incident influenced bystanders' willingness to help. The fact that bystanders in online environments are even less inclined to help the victim as compared to offline bullying (Barlińska, Szuster, \& Winiewski, 2013) renders such an investigation highly relevant.

We focused on the characteristics of the incident itself as well as the bystanders' evaluation and interpretation of such an incident. Similar to Obermaier et al.'s (2016) results, our study shows that objectively more severe incidents (containing threats and insults) are indeed ascribed a higher level of severity by those observing the incident. This, in turn, correlates with a higher intention to intervene among our participants in their role as bystanders, which is in line with Bastiaensens et al.'s (2014) findings. Therefore, the degree of emergency in a problematic situation (as indicated in our study by the existence of threats and insults as compared to only insults against the victim) is a gauge for bystanders' willingness to assist the victim in both offline situations (Shotland \& Huston, 1979) and cyber victimization.

Additionally, the more severe a bystander evaluates the perpetration to be, the less she or he ascribes blame to the victim, which is regarded as a key component of moral disengagement (DeSmet et al., 2014; Price et al., 2014). Weber et al. (2018) obtained comparable results: In a setting to investigate the role of gender-stereotyped processing in cyberbullying, the study showed that the more an incident represented a power imbalance between the perpetrator and the victim, the less the victim was ascribed guilt for being attacked by bystanders. Consequently, victims of presumably less severe incidents in particular are at risk of being blamed because potential bystanders do not evaluate these situations as critical or problematic. In such situations, they feel less responsible for intervening and participate more intensely in moral disengaging, which is linked to a lower willingness to help the victim (comparable to Obermaier et al., 2016). The actual consequences of the incident may 
still be devastating. Here, bystanders who do not help the victim but instead inflict even more hurt substantially contribute to a lasting experience of victimization (Campbell et al., 2001).

\section{Limitations}

Notwithstanding, we must note some limitations to consider when interpreting our results. Our sample is considerably biased toward the higher educational strata. Since cyberbullying is more prevalent among less educated strata (Walrave \& Heirman, 2011), these adolescents' experiences with cyberbullying might be more extensive. Being more familiar with different types and also the consequences of cyberbullying might result in a higher sensitivity toward seemingly less severe incidents. This also holds true for the participants in our sample. Participants who had observed a cyberbullying incident several times in the past rated the incident as significantly more severe than participants who had never seen such an attack of online victimization. Consequently, further research with a more educationally diverse sample is needed.

We should also question what aspects of adolescents' previous experiences with cyberbullying lead to a higher sensitivity among bystanders and therefore make them more prone to assist the victim. The same applies for the evaluation criteria we used to assess the severity of the online victimization. In our study, participants' perception of the severity of the incident was established by a broad set of items (nevertheless, these items were characterized by a high internal consistency and loaded on the same factor). This comparably broad measurement of perceived severity was motivated by our aim to cover very different considerations among bystanders when evaluating the severity of victimization online (e.g., based on potential harm to the victim or the extent to which the perpetrator subverted moral standards). However, investigating the relative relevance of different evaluation criteria could enhance our understanding of how intentions to help are formed. This is particularly important because the perceived severity constituted a key variable in the relationship between incident severity, victim blaming, and intention to help.

The same holds true for the concept of feeling responsible to intervene (step 3 in the model by Latané and Darley, 1970). We investigated this step of reasoning and attributing responsibility by relying on the concept of victim blaming as a main mechanism of moral disengagement; however, victim blaming presumably only indirectly relates to one's personal feeling of being responsible. For example, it is conceivable that a particularly severe incident accompanied by a victim's alleged misconduct could result in an intense feeling of personal responsibility (because of general moral standards to help people in emergencies), although the victim is also ascribed considerable guilt for having caused the incident (due to the supposed misconduct). More information on the dimensions of one's previous experience, on the relative importance of different evaluation criteria for assessing the severity of an incident, and on how victim blaming and the sense of personal responsibility relate to each other could inform prevention campaigns and measures at schools and among online communities.

Additionally, we used a fictive scenario with a victim and perpetrator who were unknown to the bystanders (the participants). In a real setting, bystanders could draw on more information such as personal characteristics and the bully's and the victim's past behavior, or they could draw on their own relationship to the individuals involved in the incident. Particularly, researchers have found that the victim's characteristics, such as extraversion and selfdisclosure on social networking services, influenced victim blaming (Schacter et al., 2016; Weber et al., 2013). Hence, field research is needed to better understand how such complex social relationships affect bystander behavior in cyberbullying. Field research is also needed to substantiate our knowledge of real bystander behavior, as investigating real behavior in an experimental design is not only difficult, but it also incurs ethical problems. Although real behavior and intention to act are highly correlated-in a meta-analysis of studies testing the theory of planned behavior, Armitage and Conner (2001) reported a correlation of $r=.47$-there is still a large gap between both. In our experimental study, we only investigated intentions (i.e., self-report measures of one's willingness to help), and it remains unknown how the "objective" and perceived severity as well as victim blaming would affect participants' actual support for the victim.

Moreover, we created a scenario to investigate the effect of incidents that differed in their degree of severity. We operationalized this by contrasting the effects of an attack containing insults and threats with an attack that only contained insults. While this procedure allowed us to unequivocally manipulate the degree of "objective" severity, it did not enable us to draw conclusions with respect to the question of how different types of incidents (i.e., insults 
vs. threats) affected bystanders' evaluation, interpretation, and intention to help. Particularly, qualitative research, which generates more diversified results, should focus on the consequences of different types of incidents for bystanders' intentions to comfort the victim.

One final limitation concerns the design of our study: We studied the causal mechanisms resulting from incidents with different degrees of severity on participants' perceived severity, their tendency to blame the victim, and finally, their intention to help. While the experimental manipulation allowed us to investigate the causal impact of the "objective" severity of the incident, the cross-sectional design inhibited us from drawing causal conclusions regarding the mediators and dependent variable. We can only assume the direction of effects studied here because theoretical considerations (particularly the model by Latané and Darley, 1970) suggest this direction.

\section{Conclusion}

In sum, the findings presented here add to existing research in three ways: 1) They contribute to the robustness of existing findings (due to the replication of results on the effects of incident severity). 2) They extend existing research by including mediators that have not yet been connected to each other in research on bystander behavior in cyberbullying and as such they help to investigate the cognitive process suggested by Latané and Darley (1970) in a more comprehensive way. 3) Since our study design was greatly informed by previous qualitative research, we were also able to overcome some of the methodological shortcomings of previous research on bystander behavior in cyberbullying (e.g. more realistic setting).

Therefore, our study adds evidence to our understanding of how the dynamics between perceiving, evaluating, and interpreting a cyberbullying incident-as Latané and Darley (1970) described for offline emergency situations-crucially shape bystanders' intentions to react. We paid particular attention to the phenomenon of moral disengagement in terms of attributing partial blame to the victim. Yet, the dynamics between evaluating an incident, blaming the victim for having caused it, and willingness to support the person in an emergency show that even presumably less serious incidents can cause severe harm to the victim (Tokunaga, 2010). In light of the fact that less severe incidents are often dismissed-even by teachers and parents-as being "fun" or benign teasing, our results suggest that more efforts are needed to educate the involved individuals about the severity of the consequences that seemingly harmless incidents can have. Even more so, the characteristics of online environments contribute to bystanders' potential misinterpretation of an emergency situation. They cannot directly observe how a victim is suffering from an attack, and as such, they lack information on the severity of the incident of which a victims' suffering can be indicative. They evaluate the situation based solely on the obvious characteristics of the perpetration; consequently, they may underestimate the harmful impact of the attack. Prevention programs that contain empathy training may compensate for this lack of information. In such trainings, pupils are asked to reflect on the thoughts, feelings, and motivations of perpetrators and victims after being exposed to different cyberbullying scenarios. These programs have been shown to enhance adolescents' cognitive and affective empathetic concern with the victim and to reduce cyberbullying (Schultze-Krumbholz, Schultze, Zagorscak, Wölfer, \& Scheithauer, 2016). Such prevention measures could sensitize individuals to the consequences of cyberbullying-particularly for incidents that are seemingly less severe. Moreover, school prevention programs on traditional bullying should incorporate information on the specific characteristics of bullying online (see Runions \& Bak, 2015) to educate the involved persons (school staff and pupils) about the differences (lack of information, unlimited scope, etc.) and their serious consequences for the victims. Only by making teachers, parents, and peers aware that even seemingly innocuous cyberbullying incidents may result in serious and harmful consequences will we be able to prevent victims from being hurt additionally via secondary victimization.

\section{References}

Allison, K. R., \& Bussey, K. (2016). Cyber-bystanding in context: A review of the literature on witnesses' responses to cyberbullying. Children and Youth Services Review, 65, 183-194.

https://doi.org/10.1016/j.childyouth.2016.03.026

Allison, K. R., \& Bussey, K. (2017). Individual and collective moral influences on intervention in cyberbullying. Computers in Human Behavior, 74, 7-15. https://doi.org/10.1016/j.chb.2017.04.019 
Armitage, C. J., \& Conner, M. (2001). Efficacy of the theory of planned behaviour: A meta-analytic review. British Journal of Social Psychology, 40, 471-499. https://doi.org/10.1348/014466601164939

Bandura, A. (1990). Selective activation and disengagement of moral control. Journal of Social Issues, 46, 27-46.

Barlińska, J., Szuster, A., \& Winiewski, M. (2013). Cyberbullying among adolescent bystanders: Role of the communication medium, form of violence, and empathy. Journal of Community \& Applied Social Psychology, 23, 37-51. https://doi.org/10.1002/casp.2137

Bastiaensens, S., Vandebosch, H., Poels, K., van Cleemput, K., DeSmet, A., \& De Bourdeaudhuij, I. (2014). Cyberbullying on social network sites. An experimental study into bystanders' behavioral intentions to help the victim or reinforce the bully. Computers in Human Behavior, 31, 259-271.

https://doi.org/10.1016/j.chb.2013.10.036

Bastiaensens, S., Vandebosch, H., Poels, K., van Cleemput, K., DeSmet, A., \& De Bourdeaudhuij, I. (2015). 'Can I afford to help?' How affordances of communication modalities guide bystanders' helping intentions towards harassment on social network sites. Behaviour \& Information Technology, 34, 425-435.

https://doi.org/10.1080/0144929X.2014.983979

Brody, N., \& Vangelisti, A. L., (2016). Bystander intervention in cyberbullying. Communication Monographs, 83, 94119. https://doi.org/10.1080/03637751.2015.1044256

Burger, J. M. (1981). Motivational biases in the attribution of responsibility for an accident: A meta-analysis of the defensive-attribution hypothesis. Psychological Bulletin, 90, 496-512. https://doi.org/10.1037/0033-2909.90.3.496

Campbell, R., Wasco, S. M., Ahrens, C. E., Sefl, T., \& Barnes, H. E. (2001). Preventing the "second rape": Rape survivors' experiences with community service providers. Journal of Interpersonal Violence, 16, 1239-1259. https://doi.org/10.1177/088626001016012002

Cohen, L. E., \& Felson, M. (1979). Social change and crime rate trends: A routine activity approach. American Sociological Review, 44, 588-608. https://doi.org/10.2307/2094589

DeHue, F., Bolman, C, \& Völlink, T. (2008). Cyberbullying: Youngsters' experiences and parental perception. CyberPsychology \& Behavior, 11, 217-223. https://doi.org/10.1089/cpb.2007.0008

DeSmet, A., Veldeman, C., Poels, K., Bastiaensens, S., van Cleemput, K., Vandebosch, H., \& De Bourdeaudhuij, I. (2014). Determinants of self-reported bystander behavior in cyberbullying incidents amongst adolescents. Cyberpsychology, Behavior, and Social Networking, 17, 207-215. https://doi.org/10.1089/cyber.2013.0027

Didden, R., Scholte, R. H. J., Korzilius, H., De Moor, J. M. H., Vermeulen, A., O'Reilly, M., . . Lancioni, G. E. (2009). Cyberbullying among students with intellectual and developmental disability in special education settings. Developmental Neurorehabilitation, 12, 146-151. https://doi.org/10.1080/17518420902971356

Dooley, J. J., Pyżalski, J., \& Cross, D. (2009). Cyberbullying versus face-to-face bullying: A theoretical and conceptual review. Zeitschrift für Psychologie, 217, 182-188. https://doi.org/10.1027/0044-3409.217.4.182

Dredge, R., Gleeson, J. F., \& de la Piedad Garcia, X. (2014). Risk factors associated with impact severity of cyberbullying victimization: A qualitative study of adolescent online social networking. Cyberpsychology, Behavior, and Social Networking, 17, 287-291. https://doi.org/10.1089/cyber.2013.0541

Dubrovsky, V., Kiesler, S., \& Sethna, B. (1991). The equalization phenomenon: Status effects in computermediated and face-to-face decision-making groups. Human-Computer Interaction, 6, 119-146.

https://doi.org/10.1207/s15327051hci0602_2

Field, A. (2013). Discovering statistics using IBM SPSS statistics. London: Sage. 
Hayes, A. F. (2013). Introduction to mediation, moderation, and conditional process analysis: A regression-based approach. New York: The Guilford Press.

Holfeld, B. (2014). Perceptions and attributions of bystanders to cyber bullying. Computers in Human Behavior, 38 , 1-7. https://doi.org/10.1016/j.chb.2014.05.012

Kazerooni, F., Taylor, S. H., Bazarova, N. N., \& Whitlock, J. (2018). Cyberbullying bystander intervention: The number of offenders and retweeting predict likelihood of helping a cyberbullying victim. Journal of ComputerMediated Communication, 23, 146-162. https://doi.org/10.1093/jcmc/zmy005

Kowalski, R. M., Giumetti, G. W., Schroeder, A. N., \& Lattanner, M. R. (2014). Bullying in the digital age: A critical review and meta-analysis of cyberbullying research among youth. Psychological Bulletin, 140, 1073-1137.

https://doi.org/10.1037/a0035618

Latané, B., \& Darley, J. M. (1970). The unresponsive bystander: Why doesn't he help? New York: Appleton-CenturyCrofts.

Lerner, M. (1980). The belief in a just world: A fundamental delusion. New York: Plenum Press.

Lerner, M. J., \& Miller, D. T. (1978). Just world research and the attribution process: Looking back and ahead. Psychological Bulletin, 85, 1030-1051. https://doi.org/10.1037/0033-2909.85.5.1030

Modecki, K. L., Minchin, J., Harbaugh, A. G., Guerra, N. G., \& Runions, K. C. (2014). Bullying prevalence across contexts: A meta-analysis measuring cyber and traditional bullying. Journal of Adolescent Health, 55, 602-611. https://doi.org/10.1016/j.jadohealth.2014.06.007

Namie, G., \& Lutgen-Sandvik, P. E. (2010). Active and passive accomplices: The communal character of workplace bullying. International Journal of Communication, 4, 343-373.

Obermaier, M., Fawzi, N., \& Koch, T. (2016). Bystanding or standing by? How the number of bystanders affects the intention to intervene in cyberbullying. New Media \& Society, 18, 1491-1507.

https://doi.org/10.1177/1461444814563519

Patchin, J. W., \& Hinduja, S. (2006). Bullies move beyond the schoolyard. A preliminary look at cyberbullying. Youth Violence and Juvenile Justice, 4, 148-169. https://doi.org/10.1177/1541204006286288

Patterson, L. J., Allan, A., \& Cross, D. (2017a). Adolescent bystander behavior in the school and online environments and the implications for interventions targeting cyberbullying. Journal of School Violence, 16, 361375. https://doi.org/10.1080/15388220.2016.1143835

Patterson, L. J., Allan, A., \& Cross, D. (2017b). Adolescent perceptions of bystanders' responses to cyberbullying. New Media \& Society, 19, 366-383. https://doi.org/10.1177/1461444815606369

Pratt, T. C., Holtfreter, K., \& Reisig, M. D. (2010). Routine online activity and internet fraud targeting: Extending the generality of routine activity theory. Journal of Research in Crime and Delinquency, 47, 267-296.

https://doi.org/10.1177/0022427810365903

Price, D., Green, D., Spears, B., Scrimgeour, M., Barnes, A., Geer, R., \& Johnson, B. (2014). A qualitative exploration of cyber-bystanders and moral engagement. Journal of Psychologists and Counsellors in Schools, 24, 1-17.

https://doi.org/10.1017/jgc.2013.18

Rivers, I., \& Noret, N. (2010). 'I h8 u': findings from a five-year study of text and email bullying. British Educational Research Journal, 36, 643-671. https://doi.org/10.1080/01411920903071918 
Roberto, A. J., Eden, J., Savage, M. W., Ramos-Salazar, L., \& Deiss, D. M. (2014). Prevalence and predictors of cyberbullying perpetration by high school seniors. Communication Quarterly, 62, 97-114.

https://doi.org/10.1080/01463373.2013.860906

Runions, K. C., \& Bak, M. (2015). Online moral disengagement, cyberbullying, and cyber-aggression. Cyberpsychology, Behavior, and Social Networking, 18, 400-405. https://doi.org/10.1089/cyber.2014.0670

Salmivalli, C. (2010). Bullying and the peer group: A review. Aggression and Violent Behavior, 15, 112-120. https://doi.org/10.1016/j.avb.2009.08.007

Salmivalli, C., Lagerspetz, K., Björkqvist, K., Österman, K., \& Kaukiainen, A. (1996). Bullying as a group process: Participant roles and their relations to social status within the group. Aggressive Behavior, 22, 1-15. https://doi.org/10.1002/(SICI)1098-2337(1996)22:1<1::AID-AB1>3.0.CO;2-T

Schacter, H. L., Greenberg, S., \& Juvonen, J. (2016). Who's to blame? The effects of victim disclosure on bystander reactions to cyberbullying. Computers in Human Behavior, 57, 115-121. https://doi.org/10.1016/j.chb.2015.11.018

Schultze-Krumbholz, A., Schultze, M., Zagorscak, P., Wölfer, R., \& Scheithauer, H. (2016). Feeling cybervictims' pain-The effect of empathy training on cyberbullying. Aggressive Behavior, 42, 147-156.

https://doi.org/10.1002/ab.21613

Shotland, R. L., \& Huston, T. L. (1979). Emergencies: What are they and do they influence bystanders to intervene? Journal of Personality and Social Psychology, 37, 1822-1834. https://doi.org/10.1037/0022-

3514.37.10.1822

Slonje, R., \& Smith, P. K. (2008). Cyberbullying: Another main type of bullying? Scandinavian Journal of Psychology, 49, 147-154. https://doi.org/10.1111/j.1467-9450.2007.00611.x

Song, J., \& Oh, I. (2018). Factors influencing bystanders' behavioral reactions in cyberbullying situations. Computers in Human Behavior, 78, 273-282. https://doi.org/10.1016/j.chb.2017.10.008

Thornberg, R., \& Jungert, T. (2013). Bystander behavior in bullying situations: Basic moral sensitivity, moral disengagement and defender self-efficacy. Journal of Adolescence, 36, 475-483.

https://doi.org/10.1016/j.adolescence.2013.02.003

Tokunaga, R. S. (2010). Following you home from school: A critical review and synthesis of research on cyberbullying victimization. Computers in Human Behavior, 26, 2772-87. https://doi.org/10.1016/j.chb.2009.11.014

van Cleemput, K., Vandebosch, H., \& Pabian, S. (2014). Personal characteristics and contextual factors that determine "helping," "joining in," and "doing nothing" when witnessing cyberbullying. Aggressive Behavior, 40, 383-396. https://doi.org/10.1002/ab.21534

Vandebosch, H., \& van Cleemput, K. (2009). Cyberbullying among youngsters: Profiles of bullies and victims. New Media \& Society, 11, 1349-1371. https://doi.org/10.1177/1461444809341263

Walrave, M., \& Heirman, W. (2011). Cyberbullying: Predicting victimisation and perpetration. Children \& Society, 25, 59-72. https://doi.org/10.1111/j.1099-0860.2009.00260.x

Weber, M., Koehler, C., \& Schnauber-Stockmann, A. (2018). Why should I help you? Man up! Bystanders' gender stereotypic perceptions of a cyberbullying incident. Deviant Behavior. Advance online publication. https://doi.org/ 10.1080/01639625.2018.1431183

Weber, M., Ziegele, M., \& Schnauber, A. (2013). Blaming the victim: The effects of extraversion and information disclosure on guilt attributions in cyberbullying. Cyberpsychology, Behavior, and Social Networking, 16, 254-259. 


\title{
Correspondence to:
}

Christina Koehler

Johannes Gutenberg University

Jakob-Welder-Weg 12

Mainz 55128

Germany

Email: christina.koehler(at)uni-mainz.de

Editorial record: First submission received on April, 27. Revisions received on July, 24 and November, 5. Accepted for publication on December, 10.

The article is part of the Special Issue "Bystanders of Online Aggression" guest edited by Hana Machackova (Masaryk University, Brno, Czechia), Jan Pfetsch (Technische Universität, Berlin, Germany), and Georges Steffgen (University of Luxembourg, Luxembourg).

\begin{abstract}
About Authors
Christina Koehler is a research assistant and PhD candidate at the Department of Communication, University of Mainz. Her research focuses on detrimental social effects of computer-mediated communication (esp., cyberbullying, online hate speech) and media effects on citizens' political attitudes as well as political elites' decision making.
\end{abstract}

Mathias Weber is a postdoctoral researcher at the Department of Communication, University of Mainz. His research focuses on adolescents' media use, sexual media content, and on potentially harmful online behavior. 